\title{
Drought in the U.S. Caribbean: Impacts on Tropical Forest Ecosystems
}

Authors: Shelley Crausbay, Conservation Science Partners; William Gould and Josh Fain, USDA Caribbean Climate Hub

Graphic: Integration \& Application Network, University of Maryland Center for Environmental Science

Forests in the U.S. Caribbean are spectacularly diverse, with more than 500 native tree species in Puerto Rico alone. These forests and trees provide many services to the region's 3.5 million people, including watershed and coastal protection, economic benefits from fruit and wood, cooling in urban environments, and improved water quality, recreation, habitat, and biodiversity protection. Caribbean forests range from coastal mangroves and dry forests, to rainy cloud forests on the mountain peaks. They have been shaped by frequent natural disturbances such as hurricanes, drought, flooding, landslides, and wildfire. Projected increases in temperatures and reduced or greater variability in rainfall may lead to increased drought frequency and intensity. Drought effects will vary by forest type, with greater impacts on forests adapted to perennially wet conditions. Droughts can affect the timing and amount of fruiting and flowering with cascading effects on wildlife. Droughts can affect tree productivity, with loss of leaves and reduced canopy cover affecting nutrient cycling, and the amount of sunlight reaching forest floors. Changing nutrient and environmental conditions can affect the biota and related services delivered by forests. Under a changing climate, droughts that cause tree mortality may affect forest succession, with drier adapted species replacing wetter adapted species. Drought and wildfire can lead to loss of forests and invasion of fire-adapted nonnative shrubs and grasses.

\section{About this Series}

This fact sheet is part of a series examining what we know about the impacts of drought on ecosystems and agriculture in the U.S.

Caribbean. Explore the other fact sheets on:

- Coastal Estuary Ecosystems

- Freshwater Ecosystems

- Crops

- Livestock

View the complete series here: usgs.gov/casc/IslandDrought

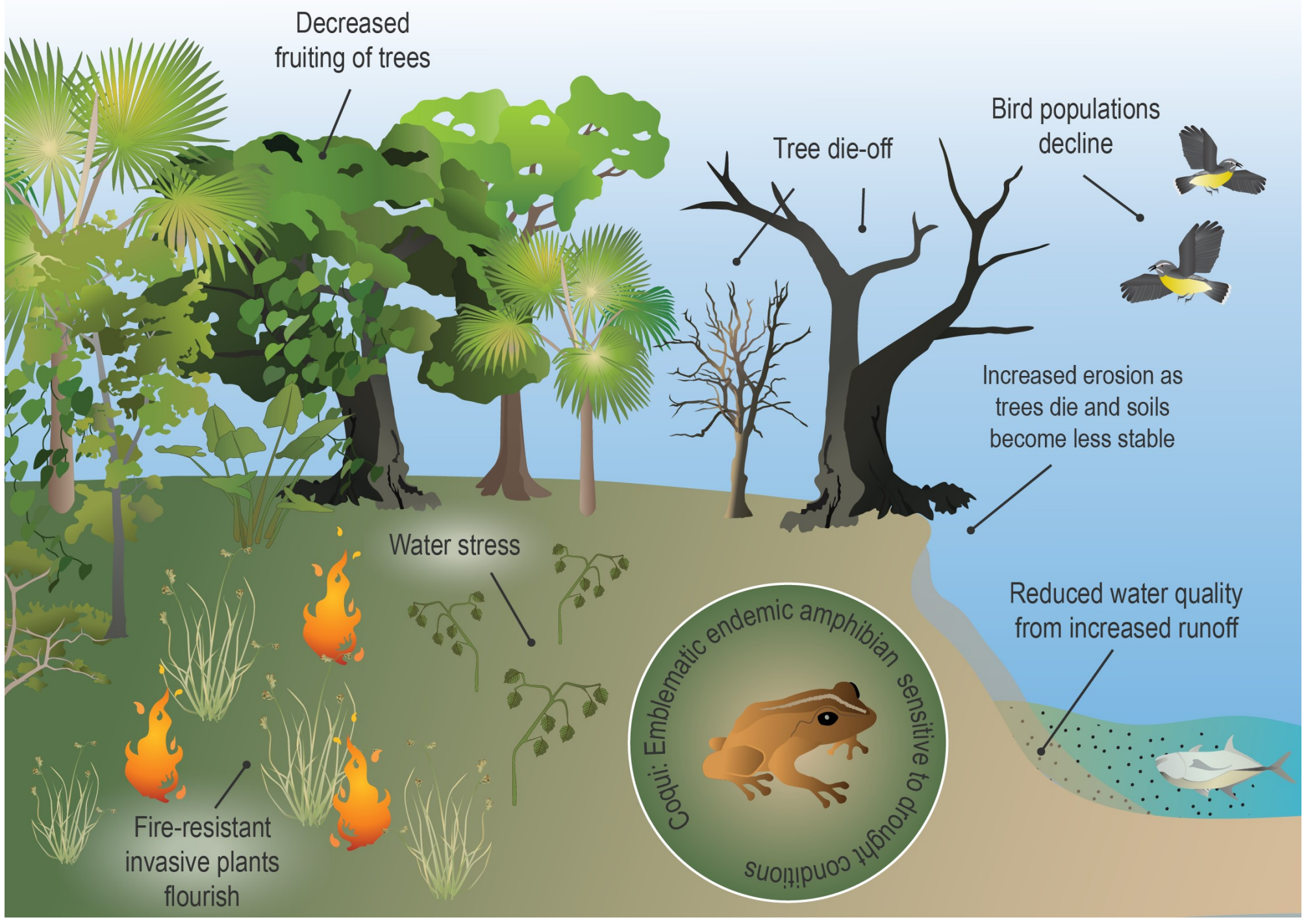


- Adaptive Capacity: Many tree and animal species are adapted to drought. Anolis lizards can regulate water loss through their skin during dry periods, and dryland tree species have smaller, thicker leaves and other adaptive traits to reduce water loss.

- Crossing Thresholds: Frogs are also adaptive and can change their physiology to prevent drying, but prolonged droughts can exceed this adaptive capacity. Juvenile Coqui are particularly sensitive to drought conditions.
- Changing Communities: Prolonged drought can change rates of reproduction for many plants and animals. The likelihood of mortality can be increased when drought and other disturbances, such as wildfire or insect outbreaks occur. Over time this can lead to shifts in species composition that persists long after a drought ends.

- Species Loss: The most vulnerable communities are those associated with the rainy cloud forests of Puerto Rico, which harbor a number of endemic and endangered plant and animal species.

\section{Landscape-Scale Effects}

- Individual droughts exhibit spatial variation in severity. In 1992, a drought occurred in Puerto Rico with impacts on consumption and rationing, but with no lasting effects on the wet forests. However, in 1994-95 a severe drought on the island of St. John caused mortality of $12 \%$ of trees - much greater than the mortality experienced after Hurricane Hugo in 1989.

- A 2015 drought that impacted the U.S. Caribbean reduced flowering and seed production in the drier Guánica State Forest. In contrast, wetter forests have shown increases in reproduction in drought years due to the increase in light availability and water stress.

\section{Gross-Sector Impacts}

In a warming climate, 21st century droughts may coincide with increased demand for water for people, agriculture, and ecosystem management. Ultimately, increasing drought frequency and severity, coupled with other disturbances and competing demands for water may lead to changes in forest plant and animal communities in the U.S. Caribbean. These changes will affect human communities through altered recreation opportunities, water quality, productivity, economic benefits, and watershed protection.

\section{Future Research Directions}

Scientists recognize the role of droughts in the health and functioning of Caribbean forests and are tracking drought effects in the Luquillo Experimental Forest. A better understanding of how droughts impact tropical forests across the Caribbean is still needed. Key questions include:

- Are dry forests more vulnerable to drought across the broad precipitation gradient in U.S. Caribbean forests?

- Are new, emergent forests that are dominated by alien species more or less vulnerable to drought?

- How do drought impacts to forests affect the natural functions people depend on, like erosion prevention and water quality?

- What plant species are likely to come in after widespread tree mortality?

- Could more frequent drought associated with climate change transform U.S. Caribbean forests?

\section{About Us}

This fact sheet is a product of the 2018 U.S. Caribbean Drought Workshop, hosted by the USDA Caribbean Climate Hub in collaboration with the Climate Adaptation Science Center (CASC) network. View a more detailed description of drought impacts on tropical forests at usgs.gov/casc/lslandDrought

CASCs: Delivering science to help fish, wildlife, water, land, and people adapt to a changing climate. Learn more: usgs.gov/casc Caribbean Climate Hub: Developing and delivering climate adaptation information. Find resources and tools at caribbeanclimatehub.org and climatehubs.oce.usda.gov/hubs/caribbean. International Institute of Tropical Forestry, Río Piedras, Puerto Rico. The USDA is an equal opportunity provider, employer and lender. 